\title{
La cirugía a través del tiempo. Extracto de Saturno: una receta médica del siglo XVIII
}

\author{
Surgery through time. Saturn extract: an 18th century medical prescription
}

Lina A. Gómez¹, Eduardo Tuta-Quintero², Ignacio Briceño-Balcázar, Angélica García², Julio Martínez-Lozano ${ }^{3}$ y Alberto Gómez-Gutiérrez ${ }^{4}$

${ }^{1}$ Centro de Investigación Biomédica (Cibus), Facultad de Medicina, Universidad de la Sabana, Chía; ${ }^{2}$ Facultad de Medicina, Universidad de La Sabana, Chía; ${ }^{3}$ Grupo Genética Humana, Facultad de Medicina, Universidad de La Sabana, Chía; ${ }^{4}$ nstituto de Genética Humana, Facultád de Medicina, Pontificia Universidad Javeriana, Bogotá. Colombia

\section{Resumen}

Objetivo: Analizar una receta médica del siglo XVIII en el Nuevo Reino de Granada, hoy República de Colombia, utiliżada para el tratamiento de las lesiones de tejidos blandos, específicamente heridas y úlceras en la piel. Método: Se realizó una búsqueda documental en el Archivo Histórico Cipriano Rodríguez Santamaría de la Biblioteca Octavio Arizmendi Posadâ, en la Universidad de La Sabana (Chía, Colombia), y se hizo una revisión de la literatura disponible en bases de datos electrónicas. Resultados y conclusión: En la receta médica colonial se mencionan los beneficios del uso de lo que se interpreta como acetato de plomo en cataplasma para procesos inflamatorios en general y alteraciones de la piel. Sin embargo, en la actualidad se conoce su potencial efecto citotóxico tisular en diversos órganos.

Palabras clave: Acetato de plomo. Cirugía general. Heridas. Inflamación. Nuevo Reino de Granada. Recetas médicas. Úlcera.

\begin{abstract}
\end{abstract}
Objective: To analyze a medical prescription from the 18th century in the New Kingdom of Granada, nowadays Colombia, used in the treatment of soft tissue injuries, specifically wounds and skin ulcers. Method: A documentary search was. ducted in the Cipriano Rodríguez Santamaria Historical Archive of the Octavio Arizmendi Posada Library, at Universidad de La Sabana (Chía, Colombia), and a review of the literature available in electronic databases. Results and conclusion:-0 The colonial medical prescription mentions the benefits of lead acetate in poultice for inflammatory processes in general and skin alterations. However, its use is not recommended due to its potential cytotoxic effect at tissue level in various organs.

Key words: Lead acetate. General surgery. Wounds. Inflammation. New Kingdom of Granada. Medical prescriptions. Ülcer.

\section{Introducción}

En el Archivo Histórico de la Biblioteca Octavio Arizmendi Posada, de la Universidad de La Sabana, ubicada en el municipio de Chía, departamento de
Cundinamarca, a unos 23 kilómetros de Bogotá (Colombia), se encuentra una colección de más de un centēnar de recetas médicas que datan de finales del siglo XVIII. Corresponden a una donación realizada por el pădre Cipriano Rodríguez Santa María, epónimo instituciơnal
Fecha de recepción: 10-07-2020 C.P. 140013 Chía, Cundinamarca, Colombia E-mail: Lina.gomez3@unisabana.edu.co 0009-7411/0 2020 Academia Mexican (http://creativecommons.org/licenses/by-nc-nd/4.0/)
Fecha de aceptación: 15-09-2020

DOI: 10.24875/CIRU.20000745
Cir Cir. 2021;89(1):135-139 Contents available at Puḅed www.cirugiaycirujanos.com 
del archivo. En este artículo se transcribe y analiza una de estas recetas, utilizada en aquella época como tratamiento para heridas y úlceras en la piel. Adicionalmente se realizó una búsqueda de la historia de la cirugía enfocada en el manejo de estas lesiones.

\section{Método}

Se llevó a cabo una búsqueda documental en el Archivo Histórico de la Biblioteca Octavio Arizmendi Posada en la Universidad de La Sabana, en el que se encuentra la receta Acerca del extracto de Saturno, y posteriormente se realizó una revisión de la literatura disponible en las bases de datos PubMed, SciELO y ClinicalKey en el periodo comprendido entre 1997 y 2017, empleando los términos de búsqueda "Acetato de plomo", "Vegeto", "Heridas", "Úlceras" y "Thomas Goulard".

\section{Resultados}

En el siglo v antes de la Era Cristiana, en el periodo comprendido entre los años 460 y 370 a.C. Hipócrates introdujo el concepto de causa y efecto en la relación entre paciente y enfermedad; además, definió la cirugía como una especialidad encargada de controlar sangrados, reconocer y tratar fracturas, dislocaciones, fístulas en ano y empiemas torácicos. También se describió el uso de apósitos de lino remojados en vino con el fin de favorecer la curación de heridas por segunda intención, y la implementación de prácticas de asepsia, generando así un gran impacto en la medicina y la cirugía de la época, algunos de cuyos principios se mantienen en la actualidad ${ }^{1-5}$. En la Edad Media aparecieron los primeros hospitales, de los cuales los más conocidos fueron los bizantinos, donde los antecesores de los cirujanos y enfermeros cuidaban pacientes con heridas usando tratamientos basados en el uso de plantas medicinales. Por esta misma época alejandrina (hasta 642), los judíos, que ya habían diseñado sus propias salas de cirugía, practicaban la sanación de heridas interviniendo los bordes de estas para conseguir una mejor cicatrización. En la Edad Media italiana destacó Hugo Borgognoni (c. 1170-1259), quien colocaba vino en las heridas ${ }^{2,3}$.

\section{El papiro de Edwin Smith}

Este papiro, originario del Antiguo Egipto, fue descubierto en 1862 por Edwin Smith (1822-1906) y data del año 1600 a.C., aunque se cree que es copia de un papiro mucho más antiguo, quizás del año 3000 a.C., y es considerado como el primer libro espēcializado en el tratamiento de las heridas. Consta dê 48 casos clínicos que se presentan según la localizaeión de la lesión y organizados según su gravedad. Gontienen la descripción semiológica y el diagnóstico, en el cual se establecía si la herida sería tratada o no, y cuál sería el tratamiento usado, presentando la solución a la lesión con un enfoque científico, no mágịico, y con comentarios complementarios que respaldaban la información contenida en el documento. Uno dêlos tratamientos descritos, que se conserva en la práctica clínica actual, son las suturas de las heridas que posteriormente eran cubiertas con vendajes hechos de tejido fino de lino. De manera general, en este papiro se describe cómo se aplicaban curaciones a basê de grasa animal, fibras de algodón y miel. El papirê de Edwin Smith tiene gran relevancia en la historia de la medicina, ya que se evidencia claramente el cambio de método en la práctica clínica, con un enfoquèe riguroso e independiente de las explicaciones yôlos enfoques sobrenaturales. Según las recomendaçiones que se encuentran en el papiro de Edwin Smith, probablemente sin saberlo, en aquella época utilizaron técnicas no adherentes, con potencial antibacteriano, que absorbían los exudados ${ }^{4}$.

\section{El extracto de Saturno}

A mediados del siglo XVIII se publicó un libró de recetas escrito por el médico francés Tomás Goulard (1697-1784), traducido al español con el título dé El cirujano instruido, en el que el autor relata su experiencia curando una variedad de enfermedades con derivados del plomo. La receta denominada «Extracto de Saturno» era, según Goulard, un método barato y fácil de curar casi cualquier afección externa. El acetatò de plomo o extracto de Saturno se aplicó en el siglo XVIII en medicina general y en cirugía, y se proclamaba al «Agua de Goulard» como una solución acuosa de acetato de plomo con alcohol que se utilizaba como trătamiento para quemaduras, contusiones, doī̄res reumáticos, hernias, inflamaciones y hasta herpes.

Charles Richard de Beauregard (c. 1720-c. 1790), otro cirujano francés que se estableció en Madridentre 1759 y 1786, fue conocido profesionalmente por su dedicación al tratamiento de la uretritis blenorrágìca, usando métodos terapéuticos a base de acetato de plomo, tratamiento que ya había sido utilizado per Thomas Goulard. La uretritis blenorrágica, la fimosis estenótica y la parafimosis eran prevalentes en 
España para aquella época, y cuando Beauregard se estableció en España, los textos urológicos de Goulard no se conocían en este país y Beauregard los mantuvo en secreto, proclamándose como el inventor de la fórmula magistral. Posteriormente, el profesor de teología Vicente Ferrer Gorraiz Beaumont y Montesa (1718-1792) reveló los «secretos» de Beauregard7.

Gorraiz reconoció al cirujano José Ignacio Carballo Nuñez de Castro (s. XVIII) como la persona que en 1783 tradujo el trabajo de Goulard y su remedio casi universal. La preparación que describía se basaba en generar acetato de plomo hirviendo vinagre con óxido de plomo, mezclado con grasa derretida, con el cual se impregnaban y enrollaban trozos de tela fina hasta obtener un cordón que se insertaba a través del meato para que el calor del cuerpo ablandara el excipiente y liberara el acetato de plomo. Thomas Goulard desarrolló otra forma de preparación diluyendo el extracto de Saturno en agua y alcohol, y de ahí el nombre de agua vegetal-mineral, agua blanca por su color lechoso como resultado de la descomposición del acetato en sulfato de plomo, o licor de Saturno, i.e., el extracto de Saturno, que fue preparado en diferentes presentaciones, como supositorios, cataplasmas, ungüentos, pomadas o soluciones de irrigación; una terapia tópica que en su momento se decía que curaba "sin cirugía» tanto fimosis como parafimosis, y se aplicó casi para cualquier condición cutánea o inflamatoria ${ }^{8}$.

Actualmente sabemos que el plomo puede encontrarse en forma inorgánica y orgánica. En forma inorgánica está presente en la tierra, el polvo y algunas pinturas; ha sido utilizado en la fabricación de armamento y también se emplea en la construcción de edificios y en elementos de producción industrial. La presentación en forma inorgánica se absorbe más fácilmente y resulta más tóxica. La forma orgánica (plomo tetra etilo) se puede encontrar en la gasolina ${ }^{9}$. En general, la contaminación por plomo puede ocurrir en el momento de su producción o durante el almacenamiento ${ }^{10}$.

Según la literatura previamente expuesta, se evidencia la importancia que alcanzó el uso del plomo en el campo de la cirugía general en el siglo XVIII para realizar un adecuado abordaje de heridas y úlceras en la piel, fomentando así el proceso de cicatrización y evitando las complicaciones frecuentes, como procesos infecciosos que deterioraban el pronóstico de los pacientes. Con el transcurrir del tiempo se ha profundizado en el conocimiento del plomo y de las implicaciones que tiene en la salud de los seres vivos y en la contaminación del planeta.

\section{Transcripción literal de la receta del documento fuente}

\section{Primera fórmula: \\ Composición del Agua de Saturno, ó Agua} Vegeto- mineral.

No hay cosa tan simple como el agua vegeto-mineral ni tópico ni efecto sean tan prontos, ni de tanta extensión.

Hacese echando en una botella de dos cuartillas de agua común una cucharadita, como las que sirven $\overline{\bar{p}}$ ara tomar café, del Extracto de Saturno, y doblar la canté de aguandiente esto es dos cucharaditas. Las cantidades del Extracto, y del Aguardiente se pueden aumentar, ó disminuir segun lo pidan las circustancias de la naturaleza de la enfermedad y de la mayor, o menor sensibilidad de la parte á que se ha de aplicar el remedio.

Primero: el agua vegeto-mineral, es un especiffico infalible contra todas las inflamaciones externas, y'especialmente contra las Optalmicas, y bien q quandöse aplica para las inflamaciones de los ojos, es menester mas circunspección sobre la cant. del extracto de Saturno, atendiendo a que un organo tan delicado, $\overline{\bar{y}} \mathrm{do}$ tado de tan rara sensibilidad como los ojos, pide. muy particular atención. Esta advertencia es muy importănte porque es cierto que el estracto de Saturno no dejara de irritar si se aplica en notable cant., y al contrario será de alivio muy pronto si se aplica en otra cant. en el principio; nueve o. diez, ò doce gotas en un vaso de agua comun, y aumentan las gotas poco, à poco y por graduacion al paso que va calmando la inflamacion.

Segundo: contra las inflamacciones sobre el timpano del oido, y las sorderas accidentales, observándo (pre) echar en el agua dobre cant. de aguardiente alcanferado respecto de la del extracto de Satürno como queda prevenido: también puede servir en estos casos el aguardiente comun del mismo modo quêen las inflamaciones de los ojos.

Tercero: Para lavar las llagas, y mojar el aparato especialmente los bordenetes, o mezclar, y planchuelas, antes de cubrirlos con el Extracto de Satiưno; cuya composicion se dará en la receta inmediata.

Quarto: Para definirlo despues de las operaciones, fomentandolas con dicha agua, y pa los dolores de costado.

Quinto: Para lavar las úlceras antiguas callosas sordidas, y corrosivas vease el Cap. de las Ulceras?

La misma agua de Saturnos sirve para hacer el Extracto de Saturno, remedio que faltaba à la Cirügia. Puedo decir que he visto embarazarse los mas 


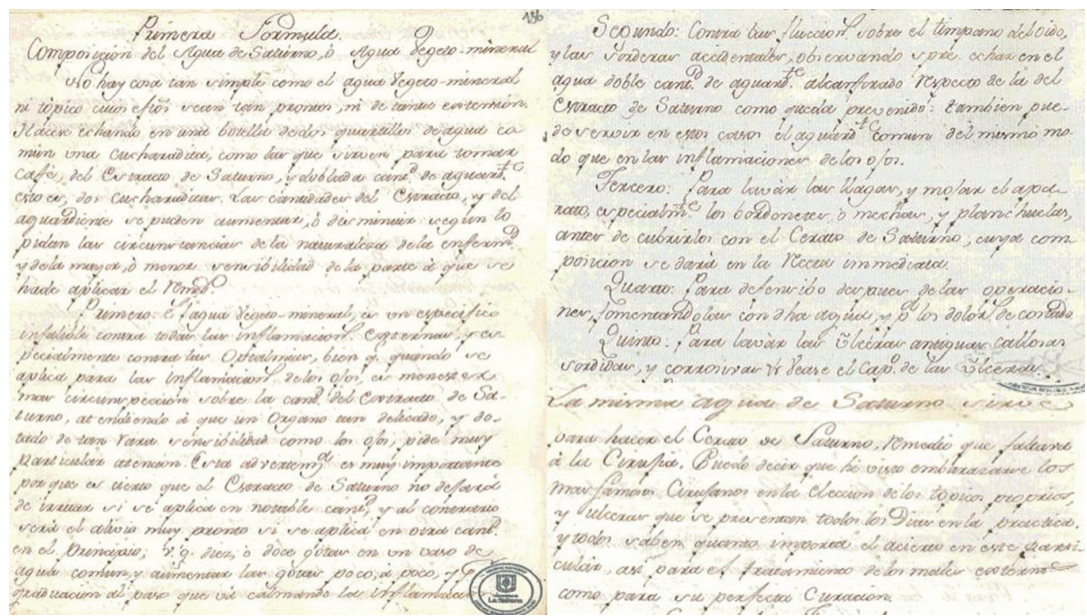

Figura 1. Receta agua de Saturno. Archivo Histórico Cipriano Rodríguez Santamaría.

famosos cirujanos en la eleccion de los topicos propios, y ulceras que se presentan todos los dias en la practica,y todos saben quanto importante es el acierto en este particular, asi para el tratamiento de los males externos como para su perfecta curación.

\section{Discusión}

El extracto de Saturno se obtenía a partir de la ebullición de vinagre con óxido de plomo mezclado con sebo derretido. Una vez este extracto se diluía en agua y alcohol, era conocido como extracto vegeto-mineral, sustancia que se usó en diferentes presentaciones como supositorios, cataplasmas, ungüentos, pomadas o soluciones de irrigación ${ }^{8}$.

Uno de los tratamientos indicados en el manejo de las úlceras más usado en el siglo XVIII fue conocido como el «método Bayton», técnica sencilla y económica que consistía en cubrir la lesión con un apósito compresivo de litargirio (óxido de plomo en lámina) o diaquilón (ungüento de óxido de plomo y aceite), que se humedecía con agua mineral, favoreciendo la "cura en ambiente húmedo»; esta técnica estimulaba el proceso de degranulación y remoción de toxinas de la lesión producto del tejido desvitalizado. Algunos autores plantean que el éxito de la terapia no radica en las sustancias usadas, sino en el vendaje compresivo que tenía el efecto de evitar la estasis venosa y disminuir el edema ${ }^{11}$.

En la receta original, a la que hacemos referencia en el presente artículo, se menciona su efecto antiinflamatorio, con aplicaciones oftálmicas, en alteraciones de los oídos, en heridas y en úlceras. En la actualidad se conocen los múltiples efectos nocivos para la salud secundarios a la exposición al plomo. La exposición intensa en un periodo breve se asocia a lesión renal agudąreversible en los túbulos proximales, glucosuria, aminoaciduria e hiperfosfaturia; con la exposición continuada a este metal también se ha documentado nefritis intersticial $^{12}$. En el sistema nervioso central, el plomo inhibe el metabolismo de la acetilcolina, lo cual altera directamente la conducción nerviosa. En el tejido óseo desplaża el calcio y posteriormente se deposita en los huesos, lo que aumenta el riesgo de fracturas. En el sistema hematopoyético se ha demostrado que altera drásticamênte la síntesis de grupo hemo, lo que conduce a una alteración en la maduración de los glóbulos rojos y postexiormente se manifiesta con anemias ${ }^{13}$.

Desde tiempos remotos se ha procurado encontrar la mejor manera de tratar las alteraciones de la piel. En la actualidad se cuenta con una amplia variedad de estrategias, como el uso de diferentes tipos de apósitos, terapias de presión negativa, antibióticos e incluso factores de crecimiento y células madre. La elecçión terapéutica dependerá de las características de càda herida y de cada paciente, teniendo en cuenta siempre la seguridad y la oportunidad del tratamiento.

\section{Conclusión}

Con el pasar del tiempo se desarrollaron recêtas médicas de origen animal, vegetal o mineral pară el manejo de las heridas y otras lesiones en la piel. Una de ellas fue a base de acetato de plomo, o extracto de Saturno, obtenido de la ebullición de vinagre con óxido de plomo mezclado con sebo derretido. En la receta médica colonial expuesta se mencionan propiedades antiinflamatorias tras su administración como catapłasma, ungüento, pomada o solución de irrigación en las 
heridas y úlceras. En la actualidad se conoce su potencial citotóxico sobre el sistema nervioso central, el aparato renal y los tejidos óseos, entre otros. No obstante, cabe señalar el memorable logro realizado por médicos y boticarios durante el periodo colonial, quienes con escasas o nulas herramientas científicas desarrollaron un tratamiento médico.

\section{Agradecimientos}

Los autores expresan su agradecimiento al Dr. Jorge Uribe Vergara por su contribución al entendimiento del contexto histórico.

\section{Financiamiento}

El proceso de investigación y publicación fue financiado por las universidades a las cuales están afiliados los autores.

\section{Conflicto de intereses}

Los autores declaran no tener ningún conflicto de intereses.

\section{Bibliografía}

1. Martínez F, Soldevilla JJ. El cuidado de las heridas. Evolución histórica (1. ${ }^{\text {a }}$ parte). Gerokomos. 1999;10:182-92.

2. De Micheli A. En torno a la evolución de los hospitales. Gac MedMex. 2005; 141:57-62.

3. Luque-Oliveros M. Los cimientos y evolución del tratamiento de las heridas quirúrgicas de la antigüedad. Disponible en: https://www.scele.org/ archivos/los cimientos de las heridas en la antiguedad.pdf $\triangle$

4. Vargas A, López M, Lillo C, Vargas MJ. El papiro de Edwin Smith y su trascendencia médica y odontológica. Rev Med Chile. 2012;140: 1357-62.

5. Toledo-Pereyra LH. Cirujanos en su siglo. De Hipócrates y su Escuela. Rev Med Hosp Gen Mex. 2014;77:3-4.

6. De Jaime Lorén JM. Thomas Goulard. Agua de Goulard (Francia, s. XVIII). Universidad CEU Cardenal Herrera, Epónimos Científicos. 2010. Disponible en: https://blog.uchceu.es/eponimos-cientificos/wp-content/ uploads/sites/24/2011/10/epo-GOULARD.pdf

7. Gómiz León J, Galindo I. Carlos Richard de Beauregard y el tratamiento de la estenosis uretral blenorrágica en el Madrid del siglo XVIH: publicidad, secreto e impostura. Act Urol Esp. 2015;39:641-5.

8. Gorraiz V. Cartilla de cirujanos y manual para todos deducida de las observaciones de Mr. Goulard. Barcelona: Imp. Herederos María Ángela Martí; 1780, 3.

9. Abadin H, Ashizawa A, Stevens YW, Llados F, Diamond G, Sage G, et al. Toxicological profile for lead. Atlanta (GA): Agency for Toxic Substances and Disease Registry (US); 2007.

10. Mushak P, Davis JM, Crocetti AF, Grant LD. Prenatal and postnatal effects of low-level lead exposure: integrated summary of a report to the U.S. Congress on childhood lead poisoning. Environ Res. 1989;50:11-36.

11. Rumbo Prieto JM, Arantón Areosa L, Delgado Fernández R. Antecédentes de la terapia compresiva: el "método Baynton" para el tratamiento de úlceras de la pierna. Gerokomos. 2017;28:49-53.

12. Poma Pedro A. Intoxicación por plomo en humanos. An Fac'đMed. 2008:69:120-6.

13. Labanda Urbano PH, Fernández García C. Saturnismo: a propósito de un caso. Med Segur Trab. 2012;58:168-73. 